IZA DP No. 7986

Ambient Temperature During Gestation and Cold-Related Adult Mortality in a

Swedish Cohort, 1915 to 2002

Tim A. Bruckner

Gerard J. van den Berg

Kirk R. Smith

Ralph A. Catalano

February 2014 


\title{
Ambient Temperature During Gestation and Cold-Related Adult Mortality in a Swedish Cohort, 1915 to 2002
}

\author{
Tim A. Bruckner \\ University of California, Irvine \\ Gerard J. van den Berg \\ University of Mannheim \\ and IZA \\ Kirk R. Smith \\ University of California, Berkeley \\ Ralph A. Catalano \\ University of California, Berkeley \\ Discussion Paper No. 7986 \\ February 2014 \\ IZA \\ P.O. Box 7240 \\ 53072 Bonn \\ Germany \\ Phone: +49-228-3894-0 \\ Fax: +49-228-3894-180 \\ E-mail: iza@iza.org
}

Any opinions expressed here are those of the author(s) and not those of IZA. Research published in this series may include views on policy, but the institute itself takes no institutional policy positions. The IZA research network is committed to the IZA Guiding Principles of Research Integrity.

The Institute for the Study of Labor (IZA) in Bonn is a local and virtual international research center and a place of communication between science, politics and business. IZA is an independent nonprofit organization supported by Deutsche Post Foundation. The center is associated with the University of Bonn and offers a stimulating research environment through its international network, workshops and conferences, data service, project support, research visits and doctoral program. IZA engages in (i) original and internationally competitive research in all fields of labor economics, (ii) development of policy concepts, and (iii) dissemination of research results and concepts to the interested public.

IZA Discussion Papers often represent preliminary work and are circulated to encourage discussion. Citation of such a paper should account for its provisional character. A revised version may be available directly from the author. 


\section{ABSTRACT \\ Ambient Temperature During Gestation and Cold-Related Adult Mortality in a Swedish Cohort, 1915 to $2002^{*}$}

For all climatic regions, mortality due to cold exceeds mortality due to heat. We examine whether cold-related mortality in adulthood varies positively with unusually benign ambient temperature during gestation, using data on over 13,500 Swedes from the Uppsala Birth Cohort Study born in 1915-1929 and followed until 2003. We link daily thermometer temperatures in Uppsala (1914 to 2002) to subjects, from their estimated date of conception onwards. We estimate survival models with time-varying explanatory variables, focusing on the two leading causes of cold-related death in adulthood: ischaemic heart disease (IHD) and stroke. An increase in the prevalence of warm temperatures during gestation leads to a significantly higher rate of mortality due to cold-related IHD. However, we do not find such a relation for cold-related stroke mortality. Additional analyses show that birthweight percentile or gestational age do not mediate discovered findings. The IHD results indicate that ambient temperature during gestation - independent of birth month - modifies the relation between cold and adult mortality.

JEL Classification: I12, Q54

Keywords: health, climate, cerebrovascular disorders, cold spells, fetal development, ischaemic heart disease, temperature regulation, migration

Corresponding author:

Tim A. Bruckner

Department of Planning, Policy, and Design

University of California at Irvine

202 Social Ecology I

Irvine, CA 92697-7075

USA

E-mail: tim.bruckner@uci.edu

\footnotetext{
* We are grateful to the UBCoS Steering Group and its Principal Investigator Ilona Koupil for permission to use the UBCoS data. We thank Bitte Modin for extensive help with the data and Scott Bartell for assistance with the analytic framework. Funding for Tim Bruckner is provided by an intramural research grant (CORCL) from the University of California, Irvine.
} 


\section{INTRODUCTION}

Populations living in Arctic and near-Arctic latitudes routinely encounter severely cold temperatures and exhibit elevated adult mortality during cold extremes (Young \& Makinen, 2010). In addition, for all three climatic regions-tropical, temperate and polar-mortality due to cold has exceeded mortality due to heat (Rau, 2007; Sheridan \& Kalkstein, 2004; Healy, 2003). A separate line of research indicates that season of birth predicts lifespan after age 50 (Doblhammer \& Vaupel, 2001). This literature, in addition to reports of temperature sensitivity during fetal development, suggests that ambient temperature during gestation may influence morbidity later in life (Morrison, Ramamurthy \& Young, 2000; Canals et al., 2009). We describe the hypothesis, and offer the first empirical test in humans, that the risk of cold-related mortality in adulthood varies positively with exposure to unusually benign ambient temperature during gestation.

Among adults, ischaemic heart disease (IHD) and cerebrovascular disease (stroke) rank as the two leading causes of cold-related death (Donaldson \& Keatinge, 1997). Although the causes of cold-related IHD and stroke appear multifactorial, research implicates two mechanisms. Thermoregulatory responses to extreme cold at older ages (e.g., after 50 years) increase arterial thrombosis via a rise in blood viscosity. An increase in blood viscosity raises the risk of a clot and, in turn, ischaemic or cerebrovascular death (Keatinge \& Donaldson, 2004). These deaths may also arise due to the rupture of lipid-containing plaques during hypertension and cold-induced coronary spasm (Farb et al., 1995). Such 
processes may act independently of other meteorological factors (e.g., humidity). Heightened morbidity due to respiratory infections (e.g., influenza) during the winter, moreover, does not account for the positive relation between cold temperature and IHD and stroke (Keatinge \& Donaldson, 2001; Kunst, Looman \& Mackenbach, 1993; Donaldson \& Keatinge, 2002).

Research further suggests that the early-life environment may adversely affect cold reactivity and increase the risk of cold-related mortality in adulthood. Fetal temperature remains relatively constant despite fluctuations in ambient temperature. However, cold during gestation may perturb development via several indirect pathways (Strand, Barnett \& Tong, 2011). Evidence from animal models indicates that the fetal response to external temperature induces longlasting sequelae on the biology of offspring (Morrison, Ramamurthy \& Young, 2000; Gluckman, Hanson \& Spencer, 2005; Lee \& Zucker, 1988).

Although less work appears in humans, Lawlor and colleagues report an association between ambient temperature after birth and subsequent IHD diagnosis among British women (Lawlor et al., 2004). This report and related literature documenting perturbations in fetal development following maternal exposure to high or low temperatures supports the "developmental plasticity" notion that cold reactivity in adulthood may vary according to ambient temperature during gestation (Bruckner, Modin \& Vågerö, 2013; Wolf \& Armstrong, 2012; and systematic review by Strand, Barnett \& Tong, 2011). We employ the term developmental plasticity to refer to the ability of a range of human phenotypes to develop from a single genotype in response to 
environmental cues during the critical period of gestation (Gluckman, Hanson \& Spencer, 2005). According to this argument, a mismatch between the temperature environment in utero and that experienced later in life may accelerate mortality in adults.

Catalano and colleagues offer a different explanation of how temperature in utero may affect mortality later in life, especially among males (Catalano, Bruckner \& Smith, 2008). They assert that cold during gestation selects especially against male fetuses least adapted to prevailing conditions. Such "culling" of frail males in utero could leave behind a smaller but hardier cohort of surviving males. The obverse of this argument, for which Catalano and colleagues find support using ecological life table data in $18^{\text {th }}$ and $19^{\text {th }}$ century Sweden, contends that male cohorts born during benign temperatures exhibit reduced lifespans when confronted with cold later in life (Catalano et al., 2012).

Taken together, previous research in humans identifies pregnancy as a critical period in which gestations adversely respond to perturbations in ambient temperature. We, however, know of no research in humans that tests whether

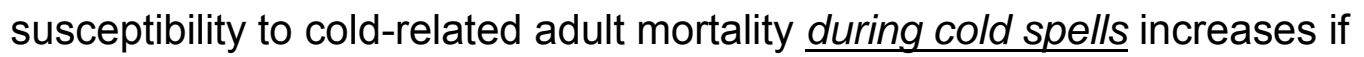
exposed to benign (i.e., non-cold) temperatures during gestation. We provide such a test using individual-level life course data from Uppsala, Sweden (Uppsala Birth Cohort Multigeneration Study, 2012). This test requires assignment of temperature exposure to individuals throughout their life-from gestation until death in adulthood. We focus on IHD and stroke mortality, the leading causes of cold-related death in adulthood. Our analytic approach controls 
for confounding by season of birth and, unlike earlier work, captures the timevarying nature of ambient temperature over the lifespan.

\section{METHODS}

Variables and Data

We retrieved data from approximately 13,500 live births delivered at Uppsala University Hospital from 1915 to 1929 . These data are linked to the Swedish Cause of Death Register until 2002 (Modin, 2002a). These births, referred to as the Uppsala Birth Cohort Study (UBCoS), are regionally representative of live births in terms of socioeconomic status and rural/urban composition. Rajaleid, Manor and Koupil (2008) further demonstrate that UBCoS is representative of births in Sweden for the years 1915-1929. UBCoS accounts for $75 \%$ of all births in the city of Uppsala and $50 \%$ of births in the surrounding region $(<20 \mathrm{~km})$ in this time period (Leon et al., 1998). UBCoS contains sociodemographic data on the mother and characteristics at birth including exact date of birth and estimated gestational age.

Researchers have linked 12,161 UBCoS birth records to 1960,1970 , and 1980 census registers as well as to cause of death data (beginning in 1952) up to December 31, 2002 (Modin, 2002a). We did not link UBCoS birth records to adult death data if the subject died in infancy $(n=852)$, out-migrated $(n=190)$, or could not be followed for other reasons $(n=422)$. This process permits cause-of-death estimates for UBCoS births up to 87 years of age (for those born in 1915). UBCoS also contains information on exact date of death. Validation tests of the 
cause-of-death field show $99.9 \%$ agreement between the death registry and the separately administered patient discharge database (Uppsala Birth Cohort Multigeneration Study, 2012). Less than $0.5 \%$ of the deceased have a nonreported cause of death. We used conventional classification schemes to categorize cause of death. We applied the following ICD codes for IHD death: 420-422 and 410-414 for ICD versions 6/7/8/9, and I20-I25 for the ICD-10 version. For stroke mortality, we applied the following codes: 330-334 for ICD-6, 430-438 for ICD versions 7/8/9, and I60-I69 for the ICD-10 version.

We retrieved the continuous, daily temperature series (in tenths of degrees centigrade) derived from thermometers in the Uppsala $\left(59^{\circ} 52^{\prime} \mathrm{N}, 17^{\circ} 38^{\prime}\right.$ E) region (Bergstrom \& Moberg, 2002). Daily temperature was calculated as the mean of hourly temperatures taken at least four times over each 24 hour period. We used the temperature series from March $1^{\text {st }}, 1914$ (i.e., earliest estimated date of conception for an UBCoS birth in 1915) to December 31, 2002 (last day of UBCoS follow-up). Consistent with conventions of climatology, scientists have homogenized and validated this publicly-available series to permit temperature comparisons across the test period (Moberg \& Bergstrom, 1997).

\section{Approach}

For each UBCoS individual with date of birth and gestational age information, we assigned an ambient temperature measure during gestation. Temperatures in Uppsala fell below $17^{\circ} \mathrm{C}$ (the nadir on the $\mathrm{J}$-shaped temperature / mortality relation: see Keatinge et al., 2000; Kunst, Looman \& 
Mackenbach, 1993) in over 95\% of all weeks in our test period. We, therefore, assumed no heat-related stress during gestation. Since our hypothesis focuses on subjects exposed to unusually benign temperatures during gestation, we specified a "benign gestation" variable as the fraction of weeks in gestation spent in the warmest quintile of Uppsala temperatures from 1915 to 1929 (i.e., $>13.5^{\circ} \mathrm{C}$, or $56.3^{\circ} \mathrm{F}$ ). This variable summarizes absolute weekly temperature values over the pregnancy and classifies any week as "benign" if temperature falls in the warmest quintile. Previous research on temperature-related birth outcomes employs this approach (Deschênes, Greenstone \& Guryan, 2009). For UBCoS subjects, the proportion of the gestation spent in the warmest quintile ranged from 0.0 to 0.44 . We also summarized weekly temperatures as the mean over the entire gestation to assess sensitivity of results to the "benign gestation" classification.

The literature on cold-related mortality does not converge on a definition for an acute cold spell (Hong et al., 2003). Research, however, finds non-linear relationships between cold and mortality such that extreme cold events exert the largest IHD and stroke mortality response (Patz et al., 2000). Consistent with this logic and previous climatic research (Reid et al., 2012), we classified extreme cold days as those that fell below the lowest $5^{\text {th }}$ percentile of the average daily temperature for each of the conventional 30-year climate normal periods spanning from 1915 to 2002 (see World Meteorological Association, 2011, for more details). For example, the $5^{\text {th }}$ percentile of daily temperature in Uppsala is $-6.4^{\circ} \mathrm{C}\left(20.5^{\circ} \mathrm{F}\right)$ for the current climate normal period (i.e., after 1990). 
Since the risk of death reportedly remains elevated for one week after extreme cold (Donaldson and Keatinge, 1997; Hong et al., 2003), we defined a daily binary indicator as " 1 " if at least one extreme cold day occurred in the past six days. This coding yields a sequence of days for which the indicator is " 1 ". Such sequences serve as our "cold spells." For example, if January 3rd and 6th, 1972 (but not other days in that month) qualified as extreme cold days, then we would score the period January 3rd through January 12th (inclusive) as a cold spell, whereas all other days in January would receive a " 0 " (not in a cold spell). Based on this logic and our temperature classification rules, we identified 586 cold spells, of varying lengths, from January 1, 1915 to December 31, 2002, that an UBCoS subject has the potential to experience.

In a life-course setting, a key challenge of estimating cold-related IHD and stroke deaths involves their conditional dependence on survival to older ages. Selective mortality of frail individuals before older ages, either in response to earlier cold spells or to other insults, may leave behind a non-representative group of older adults (Keatinge and Donaldson, 2004). One recommended approach to control health selection involves a counting process style of data input (Therneau \& Grambsch, 2010). This time-to-event strategy, which takes the functional form of a standard Cox proportional hazards model with timedependent covariates, statistically adjusts for the dependence of older-age mortality on the ability to survive to older age.

Our analysis allows the risk of mortality to vary over the life course based on time-varying characteristics. The counting process form of data input divides 
each subject's person-time of observation into discrete intervals of mortality risk, beginning at the left-truncated date of study entry (in our case, January $1^{\text {st }}, 1952$, the first day in which cause-of death data are available for the UBCoS subjects). For our test, each discrete interval (in days) receives a cold spell classification (1 or 0 ) that identifies the temperature through which the individual progresses. Failure to survive beyond a particular interval precludes the subject's exposure to temperatures at future intervals. Furthermore, persons do not contribute time intervals of observation after they die of IHD or stroke, or are lost to follow-up (via deaths due to competing risks, emigration, or survival to the last day of observation).

Our estimation strategy uses a Cox proportional hazards model of the following form. Let $\mathrm{T}$ denote current calendar time. We express the causespecific mortality rate $\theta$ of an individual at a given point of time in terms of their age $t$, a vector of birth characteristics $\mathbf{X}(\mathrm{t})$, current temperature conditions $\mathrm{C}(\mathrm{T})$, temperature in gestation $\mathrm{S}(\mathrm{T}-\mathrm{t})$, and the interaction term of temperature in gestation and current temperature conditions.

$$
\log \theta(t \mid \lambda(t), X(t), C(T), S(T-t))=\beta_{0}+\lambda_{t}+\beta^{\prime} X_{t}+\beta_{1} C_{T}+\beta_{2} S_{T-t}+\beta_{3} C_{T} S_{T-t}
$$

Where:

$\theta$ is the IHD mortality rate. In a separate specification, we examine stroke death.

$\lambda_{t}$ is the age-dependent risk of mortality at age $t$.

$\mathbf{X}_{t}$ is a vector that includes binary indicator variables for month of birth (Jan, Feb, etc.), infant sex ("1" for male, "0" for female), and binary 
indicator variables for father's occupation, a measure of socioeconomic status at birth.

$\mathrm{C}_{T}$ is the binary cold spell variable for that particular time interval.

$\mathrm{S}_{\mathrm{T}-\mathrm{t}}$ is the temperature variable during gestation, scored as the fraction of weeks in gestation spent in the highest temperature quintile $\left(>13.5^{\circ} \mathrm{C}\right)$. $\mathrm{C}_{\mathrm{T}} \mathrm{S}_{\mathrm{T}-\mathrm{t}}$ is the product of $\mathrm{S}_{\mathrm{T}-\mathrm{t}}$ and $\mathrm{C}_{\mathrm{T}}$. This "warm $\mathrm{x}$ cold" interaction term takes on a non-zero value during cold spells. The attendant coefficient $\beta_{3}$ is our parameter of interest.

The approach above explicitly controls for the subject's age-specific mortality risk at each discrete time interval. We, therefore, do not include a "rightside" age covariate in $\mathbf{X}_{t}$ in the hazards model. Per convention, we also do not cluster standard error estimates by subject (Therneau and Grambsch, 2010). We performed all analyses using SAS statistical software (proc PHREG; Cary, NC).

The start date for the principal analysis begins on January 1, 1952, the first day for which researchers linked cause of death information to UBCoS subjects. In additional sensitivity tests, we examine whether health selection before 1952 influences our results. This sensitivity check gauges the likelihood that the potentially non-representative nature of healthier UBCoS members surviving to 1952 attenuates our results.

Given that Catalano and colleagues' (2012) male-specific culling hypothesis predicts only a male response, in a separate model we test a threeway multiplicative interaction term of infant sex, the temperature variable during gestation, and the binary cold spell variable (with inclusion of the relevant two- 
way interaction terms: male $\mathrm{x}$ cold spell, male $\mathrm{x}$ temperature in gestation, and cold spell $x$ temperature in gestation). The three-way interaction term takes a non-zero, positive value only among males during cold spells.

\section{RESULTS}

Our sample comprised 13,625 liveborn subjects with plausible gestational age information and followed after birth (Table 1). The mean ambient temperature during gestation was $5.0^{\circ} \mathrm{C}$. Subjects experienced the warmest temperature quintile $\left(>13.5^{\circ} \mathrm{C}\right)$ for an average of $19 \%$ of their gestation. Almost $85 \%$ of subjects survived to age 50 and over half lived to the end of the observation period. After age 50, deaths due to IHD account for over a quarter of all recorded deaths. Less than seven percent of the total IHD and stroke deaths occur before age 50 .

Figure 1 plots, by calendar month of birth, the proportion of the gestation exposed to the warmest temperature quintile for a random sample $(n=4,000)$ of the 13,625 subjects. The temperature variable shows strong seasonality with the warmest gestations being born in the fall months. Within each birth month, gestational temperature shows substantial variation.

We display the coefficients for proportional hazards models for IHD (Table 2) and stroke (Table 3) death with January 1, 1952 as the start date of follow-up (540,450 person-years of observation). For each outcome, we consider Model 3 (right column) the final model in that it contains all relevant control variables and the warm gestation-to-cold-spell interaction term of interest. Males more than 
females show an elevated risk of IHD death. The risk of IHD death also varies positively with births in January and February (relative to births in December).

For IHD deaths, the warm gestation to cold spell interaction term indicates an increased risk of IHD death among persons subjected to warm gestations but confronted with cold spells later in life. Figure 2 displays the relation between the warm gestation $\mathrm{x}$ cold spell interaction term and IHD mortality. We plot the point estimates of the antilog of the coefficients (i.e., the hazard ratios [HR]), as well as their $95 \%$ confidence intervals $[\mathrm{Cl}]$, across the temperature values during gestation in our dataset. For subjects that spent more than $25 \%$ of their gestation in the warmest quintile, we estimate an increased risk of IHD death in cold spells (relative to non-cold intervals). Thirty percent of the UBCoS population scores above this level, which (based on the model) places them at an increased risk of a cold-related IHD death later in life (using conventional levels of statistical

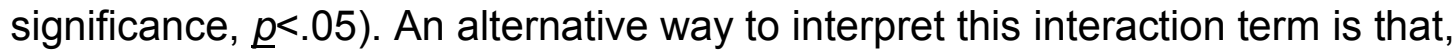
within a given cold spell in adulthood, the hazard of IHD death rises $16 \%(\mathrm{HR}=$ 1.16; $95 \% \mathrm{Cl}: 1.03-1.29)$ for each one standard deviation (SD) increase of exposure during gestation to the warmest temperature quintile $(1 \mathrm{SD}=6 \%$ more warm days in gestation).

Table 3 indicates an elevated risk of stroke death among males. Calendar month of birth does not predict the risk of stroke death later in life. Unlike the IHD results, we observe no relation between the warm gestation $\mathrm{x}$ cold spell interaction term and stroke mortality (coef. $=-0.58 ; 95 \% \mathrm{Cl}:-4.01-2.85$ ). 
We then examined the potential male-specific relation between warm gestations and cold-related mortality later in life. We repeated the tests shown in Tables 2 and 3 but included a three-way interaction term (male $\mathrm{x}$ warm gestation x cold spell) as well as all attendant two-way interaction terms. In both the IHD and stroke analysis, the three-way interaction term shows no relation to mortality risk (full results available upon request). Stratum-specific analyses by sex also indicate no elevated warm gestation $\mathrm{x}$ cold spell coefficients among males.

Although our hypothesis pertains to the warm gestation $\mathrm{x}$ cold spell interaction term, we also examined in separate models the coefficients of the two "main effect" temperature terms in the absence of the interaction variable. In both the IHD and stroke models, we cannot reject the null for the warm gestation variable. For the adult cold spell main effect, we find elevated IHD in adulthood when we specify temperature in a continuous form $\left(\mathrm{HR}\right.$ for $1^{\circ} \mathrm{C}$ reduction in temperature $=1.01 ; 95 \% \mathrm{Cl}: 1.00-1.02)$. Results for stroke cannot reject the null (full results not shown).

The positive association between the warm gestation $\mathrm{x}$ cold spell term and cold-related IHD mortality led us to explore birth characteristics that may mediate this relation. Preterm delivery and/or birthweight-for-gestational age, for example, may respond to temperature in gestation and influence later-life susceptibility to cold (Bruckner, Modin, \& Vågerö, 2013). To explore this possibility, we repeated the estimation for IHD but included gestational age and, separately, birthweight for-gestational age percentile as covariates. The coefficient and $95 \% \mathrm{Cl}$ for the 
warm gestation $\mathrm{x}$ cold spell interaction term remained essentially unchanged from that shown in Table 2 (results available upon request).

To assist the reader with gauging the magnitude of the IHD results, we calculated the fraction of IHD deaths during cold spells statistically attributable to a warm gestation. In our cohort, $173 \mathrm{IHD}$ deaths occurred during cold spells. We classified 76 of these subjects as having spent more than 25 percent of their gestation in warmest quintile (see Figure 2). We then applied to these subjects the crude hazard ratio (i.e., 1.34) of a cold-related IHD death for a warm, relative to a non-warm, gestation. Application of the attributable risk percent calculation to this crude hazard ratio yields, among persons exposed to a warm gestation, an estimated $25 \%$ of cold-related IHD deaths later in life statistically attributable to the warm gestation. Relative to all IHD deaths that occur in both cold and noncold periods, the "warm gestation" effect statistically accounts for about $3.3 \%$ of all IHD deaths in the UBCoS cohort.

Sensitivity analyses

We assessed whether health selection before 1952 (the first year in which cause-of-death data were available) influenced our results. First, we re-analyzed the data using all person-years of observation from birth to death (including before 1952). Inference for all coefficients remained unchanged from those reported in our Tables. Second, we tested the relation between the warm gestation $\mathrm{x}$ cold spell interaction term and all-cause mortality before 1952 to determine if this temperature sensitivity increased the risk of death at earlier 
ages. We found no such association. Taken together, health selection before 1952 does not appear to affect inference from our tests.

Although not central to our hypothesis, we explored whether the warm gestation $\mathrm{x}$ cold spell interaction term predicted overall, all-cause mortality. We repeated the analyses described in Equation [1] but replaced the dependent variable with all cause mortality after 1952. Results cannot reject the null (warm gestation $x$ cold spell interaction coef. $=0.36 ; 95 \% \mathrm{Cl}:-0.54-1.26)$.

We then assessed the stability of our main coefficients across various age ranges in adulthood (e.g., 30 to 60 years, 55 years or more). We found no substantial change in the magnitude of the temperature coefficients, although the standard errors increased owing to less precision from analyzing fewer deaths within a narrower age range. In addition, we assessed whether results appear sensitive to our definition of a cold spell by re-classifying cold spell intervals over the entire life course as those with days below the $10^{\text {th }}$ percentile of temperature (instead of $<5^{\text {th }}$ percentile). Statistical inference remained the same as in Tables 2 and 3.

We also specified mean temperature during gestation in its continuous form to assess sensitivity of results to the "benign" gestational temperature classification. Results, other than the metric of the IHD and stroke coefficients, did not appreciably change from those shown in Tables 2 and 3 (available upon request). The consistency of results converges with our expectation given the strong correlation $\left(R^{2}=0.80\right)$ between mean temperature during gestation and the proportion of the gestation spent in the warmest quintile. 


\section{DISCUSSION}

We tested whether Swedes whose mothers were subjected to unusually benign ambient temperatures during their gestation exhibit an elevated risk of cold-related mortality in adulthood. This hypothesis arises from literature that documents both ambient temperature sensitivity during gestation and an influence of the prenatal environment on subsequent cold reactivity, adult ischaemic heart disease (IHD) and stroke deaths. Using a high-quality longitudinal dataset from Uppsala, Sweden, we find an increased risk of IHD death during cold spells among adults whose mothers experienced relatively warm ambient temperature during pregnancy. We, however, observe no relation for stroke mortality. To our knowledge, the IHD results provide the first evidence that ambient temperature during gestation-independent of season of birthpredicts cold-related mortality later in life.

The IHD mortality findings cannot arise from seasonal factors strongly correlated with month of birth (e.g., rainfall, infectious disease burden, fertility timing, business cycles) since we controlled for month of birth in all analyses (Maccini \& Yang, 2009; Doblhammer \& Vaupel, 2001; Darrow et al., 2009; van den Berg et al., 2010). Results also do not appear mediated by birthweight or gestational duration. In addition, sensitivity tests indicate that health selection before adulthood does not account for our findings. Adjustment for birth year further minimizes confounding by shared secular trends (from 1915 to 1929) between rising temperatures and IHD mortality for the annual UBCoS birth cohorts. 
Strengths of our approach include use of what we believe to be the highest quality individual-level cohort and simultaneous local temperature data in the world. Such information allows for assignment of ambient temperature measurements during gestation, as well as longitudinal examination (for up to 87 years) of specific causes of death. In addition, unlike earlier work, our approach makes explicit the multiple exposure "opportunities" to cold spells over the life course (Lawlor et al., 2004; Catalano et al., 2012). This approach allows the risk of mortality to vary over time according to changes in ambient temperature. We also examine subjects from Sweden, one of the most populous countries in a near-Arctic climate whose birth cohorts are forced to adapt to cold.

The exogenous nature of our independent variables-derived from ambient temperature measurements-minimizes confounding by social, economic, and behavioral causes of IHD and stroke mortality. We, however, believe that two potential confounders merit discussion. First, the decision to emigrate from Sweden may not occur randomly across socioeconomic groups. Given that certain socioeconomic groups may respond more sensitively to cold spells, confounding could occur if cold-sensitive populations preferentially emigrated during a cold spell. We examined whether the 190 UBCoS subjects that emigrated showed any pattern (by socioeconomic and cold spell status) that deviated from chance. A tabular Chi-square analysis could not reject the null of random emigration $\left(X^{2}=1.25, p=0.74\right)$. Second, in $19^{\text {th }}$ century Sweden, certain socioeconomic groups disproportionately married during the December Christmas holiday to avoid disruption with work schedules. To the extent that this 
process occurred in the $20^{\text {th }}$ century, it may have yielded a select group of births nine months later that differ systematically from births in other months (Dribe \& van de Putte, 2012). To adjust for the possibility of fundamental differences of cohorts across calendar months, we controlled for month of birth as well as socioeconomic status. We note, however, that other research using UBCoS data finds no evidence of fertility timing around business cycles (van den Berg \& Modin, 2013). This result indicates that, to the extent that fine-tuning of fertility timing proved difficult, confounding of our results by this practice seems unlikely.

The absence of information on residential location precluded a spatial analysis of temperature exposures over the life course. As a proxy, we used validated daily temperatures in Uppsala, Sweden from 1915 to 2002. These daily temperatures correlate quite strongly with temperatures from urban centers in Sweden to which Uppsala residents may likely move (e.g., $R^{2}=0.997$ with temperatures in Stockholm). In addition, we could not link mortality data to UBCoS subjects that migrated out of Sweden. We, therefore, excluded subjects after their date of emigration $(n=190)$. The lack of instrument-based measurements of other meteorological factors (e.g., humidity, rainfall) or indoor temperature also did not allow for testing other life-course predictors of climaterelated mortality (van den Berg, Doblhammer \& Christensen, 2009).

Identification of biological or behavioral pathways that account for the discovered relation between warm temperatures during gestation and coldrelated IHD deaths would strengthen the evidence base in this relatively understudied area. Elucidation of potential pathways (e.g., temperature change 
causing maternal inhalation during pregnancy of smoke or particulate matter from coal-burning stoves) would also inform whether developmental plasticity (Strand, Barnett \& Tong, 2011; Barker, 1998) or selection in utero (Catalano, Bruckner \& Smith, 2008) best describes our pattern of results. Whereas the failure to observe male-specific reactivity detracts from the male-specific culling argument, Uppsala births from 1915 to 1929 may have experienced less selection pressure in utero than the $18^{\text {th }}$ and $19^{\text {th }}$ century Swedish populations examined in previous studies (Catalano, Bruckner \& Smith, 2008, Catalano et al., 2012).

Forecasts of rising temperatures have understandably stimulated research on the potential health sequelae of ambient heat. Cold, however, causes more deaths than does heat and remains an important public health concern (Rau, 2007; Analitis et al., 2008). Our investigation of a Swedish cohort indicates that the risk of IHD mortality, the leading cause of cold-related death, rises among persons whose mothers were pregnant during a relatively warm period. This finding, if replicated in other cohorts, holds two principal implications. First, results should encourage longitudinal studies on the extent to which cold, or hot, ambient temperatures in utero up- or down- regulate thermoregulatory processes later in life. Second, public health efforts to reduce cold-related morbidity may want to focus on elderly subgroups that, based on temperature exposures early in life, appear most susceptible to cold extremes. These subgroups may include the large fraction of recent Swedish immigrants from tropical climates (van den Berg et al., 2009). 


\section{REFERENCES}

Analitis, A., Katsouyanni, K., Biggeri, A., Baccini, M., Forsberg, B., Bisanti, L., Kirchmayer, U., Ballester, F., Cadum, E., Goodman, P. G., et al. (2008). Effects of cold weather on mortality: results from 15 European cities within the PHEWE project. Am J Epidemiol, 168(12), 1397-1408.

Barker, D.J. (1998). In utero programming of chronic disease. Clin Sci., 95, 115128.

Bergström, H., \& Moberg, A. (2002). Daily air temperature and pressure series for Uppsala (1722-1998). Climate Change. 53, 213-252 (updated series: http://www.smhi.se/klimatdata/meteorologi/temperatur/1.2855).

Bruckner, T. A., Modin, B., \& Vagero, D. (2013). Cold ambient temperature in utero and birth outcomes in Uppsala, Sweden, 1915-1929. Ann Epidemiol. (doi: http://dx.doi.org/10.1016/j.annepidem.2013.11.005)

Canals, M., Figueroa, D.P., Miranda, J.P., \& Sabat, P. (2009). Effect of gestational and postnatal environmental temperature on metabolic rate in the altricial rodent, Phyllotis darwini. J Therm Biol,, 34, 310-314.

Catalano, R., Bruckner, T., \& Smith, K.R. Ambient temperature predicts sex 
ratios and male longevity. (2008). Proc Natl Acad Sci U S A., 105, 2244-2247.

Catalano, R., Bruckner, T., Smith, K.R., \& Saxton, K. (2012). Temperature oscillations may shorten male lifespan via natural selection in utero. Climatic Change, 110, 697-707.

Darrow, L.A., Strickland, M.J., Klein, M., Klein, M., Waller, L.A., Flanders, D., Correa, A., Marcus, M., \& Tolbert, P.E. (2009). Seasonality of birth and implications for temporal studies of preterm birth. Epidemiology, 20, 699-706.

Deschênes, O., Greenstone, M., \& Guryan, J. (2009). Climate Change and Birth Weight. Am Econ Rev. 99, 211-217.

Doblhammer, G., \& Vaupel, J.W. (2001). Lifespan depends on month of birth. Proc Natl Acad Sci U S A, 98, 2934-2939.

Donaldson, G.C., \& Keatinge, W.R. (1997). Early increases in ischaemic heart disease mortality dissociated from and later changes associated with respiratory mortality after cold weather in south east England. J Epidemiol Community Health, 51, 643-648.

Donaldson, G.C., \& Keatinge, W.R. (2002). Excess winter mortality: influenza or cold stress? Observational study. BMJ, 324, 89-90. 
Dribe, M. \& van de Putte, B. (2012). Marriage seasonality and the industrious revolution: southern Sweden, 1690-1895. Economic History Review, 65, 3, $1123-1146$.

Farb, A., Tang, A.L., Burke, A.P., et al. (1995). Sudden coronary death.

Frequency of active coronary lesions, inactive coronary lesions, and myocardial infarction. Circulation, 92, 1701-1709.

Gluckman, P.D., Hanson, M.A., \& Spencer, H.G. (2005) Predictive adaptive responses and human evolution. TREE. 20, 527-533.

Healy, J.D. Excess winter mortality in Europe: a cross country analysis identifying key risk factors. (2003). J Epidemiol Community Health, 57, 784-789.

Hong, Y.C., Rha, J.H., Lee, J.T., et al. (2003). Ischaemic stroke associated with decrease in temperature. Epidemiology, 14, 473-478.

Keatinge, W.R., \& Donaldson, G.C. (2001). Mortality related to cold and air pollution in London after allowance for effects of associated weather patterns. Environ Res, 86, 209-216.

Keatinge, W.R., \& Donaldson, G.C. (2004). The impact of global warming on 
health and mortality. South Med J, 97, 1093-1099.

Keatinge, W.R., Donaldson, G.C., Cordioli, E., et al. (2000). Heat related mortality in warm and cold regions of Europe: observational study. BMJ., 321, 670-673.

Kunst, A.E., Looman, C.W., \& Mackenbach, J.P. (1993). Outdoor air temperature and mortality in The Netherlands: a time-series analysis. Am J Epidemiol, 137, $331-341$.

Lawlor, D.A., Davey Smith, G., Mitchell, R., et al. (2004). Temperature at birth, coronary heart disease, and insulin resistance: cross sectional analyses of the British women's heart and health study. Heart, 90, 381-388.

Lee, T.M., \& Zucker, I. (1988). Vole infant development is influenced perinatally by maternal photoperiodic history. Am J Physiol Regul Integr Comp Physiol. 255, R831-838.

Leon, D.A., Lithell, H.O., Vågerö, D., Koupilova, I., Mohsen, R., Berglund, L., Lithell, U.B., \& McKeigue, P.M. (1998). Reduced fetal growth rate and increased risk of death from ischaemic heart disease: cohort study of 15000 Swedish men and women born 1915-29. BMJ, 317, 241-245. 
Maccini, S., \& Yang, D. (2009). Under the Weather: Health, Schooling, and Economic Consequences of Early-Life Rainfall. Am Econ Rev, 99, 1006-1026.

Moberg, A., \& Bergström, H. (1997). Homogenization of Swedish temperature data. The long temperature records from Uppsala and Stockholm. Int $J$ Climatology.; 17, 667-699.

Modin, B. (2002a). Birth order and mortality: a life-long follow-up of 14,200 boys and girls born in early 20th century Sweden. Soc Sci Med.; 54, 1051-1064.

Modin, B. (2002b). Setting the scene for life. Longitudinal studies of early social disadvantage and later life chances. Centre for Health Equity Studies, Stockholm University/Karolinska Institutet. Stockholm: Almqvist \& Wiksell.

Morrison, S.F., Ramamurthy, S., \& Young, J.B. (2000). Reduced rearing temperature augments responses in sympathetic outflow to brown adipose tissue. J Neurosci, 20, 9264-9271.

Patz, J.A., McGeehin, M.A., Bernard, S.M., Ebi, K.L., Epstein, P.R., Grambsch, A., Gubler, D. J., Reither, P., Romieu, I., Rose, J.B., et al. (2000). The potential health impacts of climate variability and change for the United States: executive summary of the report of the health sector of the U.S. National Assessment. Environ Health Perspect. 108, 367-376. 
Rajaleid, K., Manor, O., \& Koupil, I. (2008). Does the strength of the association between foetal growth rate and ischaemic heart disease mortality differ by social circumstances in early or later life? J Epidemiol Community Health, 62(5), e6.

Rau, R. (2007). Seasonality in human mortality: a demographic approach. Berlin; Springer-Verlag; 2007.

Reid, C.E., Mann, J.K., Alfasso, R., English, P.B., King, G.C., Lincoln, R.A., Margolis, H.G., Rubado, D.J., Sabato, J.E., West, N.L., et al. (2012). Evaluation of a heat vulnerability index on abnormally hot days: an environmental public health tracking study. Environ Health Perspect, 120, 715-720.

Sheridan, S.C., \& Kalkstein, L.S. (2004). Progress in heat watch-warning system technology. Bull Amer Meteor Soc, 82, 1931-1941.

Smith, K.R., \& Ezzati, M. (2005). How environmental health risks change with development: the epidemiologic and environmental risk transitions revisited. Annu Rev Energy Resour, 30, 291-333

Strand, L.B., Barnett, A.G., \& Tong, S. (2011). The influence of season and ambient temperature on birth outcomes: a review of the epidemiological literature. Environ Res. 111, 451-462. 
Therneau, T.M., \& Grambsch, P.M. (2010). Modeling survival data: extending the Cox model. (pp. 68-77). New York: Springer.

Uppsala Birth Cohort Multigeneration Study. Centre for Health Equity Studies, Stockholm University. Available at:

http://www2.chess.su.se/ubcosmg/hd/methhospd.htm (accessed on August 20th, 2012).

van den Berg, G.J., Deeg, D., Lindeboom, M., \& Portrait, F.R.M. (2010). The role of early-life conditions in the cognitive decline due to adverse events later in life. Economic Journal., 120, 411-428.

van den Berg, G.J., Doblhammer, G., \& Christensen, K. (2009). Exogenous determinants of early-life conditions, and mortality later in life. Soc Sci Med, 68, 1591-1598.

van den Berg, G.J., Lundborg, P., Nystedt, P., \& Rooth, D.-O. (2009). Critical periods during childhood and adolescence: A study of adult height among immigrant siblings, Working paper, IZA Bonn and IFAU Uppsala.

van den Berg, G.J., \& Modin, B. (2013). Economic conditions at birth, birth weight, ability, and the causal path to cardiovascular mortality, Working paper, IZA Bonn and CEPR London. 
Wolf, J., \& Armstrong, B. (2012). The association of season and temperature with adverse pregnancy outcome in two German states, a time-series analysis. PLoS One, 7(7), e40228.

World Meteorological Organization. (2011). "Characterizing Climate from Datasets (Ch 4)." In: Guide to Climatological Practices. World Meteorological Organization, WMO-No. 100. (ISBN 978-92-63-10100-6).

Young, T.K., \& Makinen, T.M. (2010). The health of Arctic populations: Does cold matter? Am J Hum Biol, 22, 129-133. 
Table 1. Birth and survival characteristics of UBCoS study participants born in Uppsala, Sweden, 1915-1929 and followed until December 31, 2002.

\begin{tabular}{|c|c|c|c|}
\hline & $\mathbf{n}$ & $\%$ & Mean (SD) \\
\hline Temperature during gestation (in ${ }^{\circ} \mathrm{C}$ ) & & & $5.0(2.4)$ \\
\hline $\begin{array}{l}\text { Proportion of the gestation spent in warmest } \\
\text { temperature quintile }\left(>13.5^{\circ} \mathrm{C}\right)\end{array}$ & & & $0.19(0.09)$ \\
\hline Gestational Age (in weeks) & & & $39.7(2.3)$ \\
\hline Birth weight-for-gestational age percentile & & & $49.0(29.1)$ \\
\hline Birth length $(\mathrm{cm})$ & & & $50.6(2.7)$ \\
\hline Male & 7,133 & 52.3 & \\
\hline \multicolumn{4}{|l|}{ Father's occupation } \\
\hline Non-manual laborer & 2,058 & 15.1 & \\
\hline Manual laborer & 8,069 & 59.2 & \\
\hline Entrepreneur or farmer & 2,351 & 17.3 & \\
\hline Not classified & 1,147 & 8.4 & \\
\hline Successfully tracked to 1 year or infant death & 13,625 & 100.0 & \\
\hline Survived to 1 year & 12,773 & 93.7 & \\
\hline Survived to 50 years & 11,495 & 84.4 & \\
\hline Survived to December 31, 2002 & 7,004 & 51.4 & \\
\hline \multicolumn{4}{|l|}{ Died after 50 years but before 2003} \\
\hline Ischaemic heart death & 1,234 & 26.2 & \\
\hline Cerebrovascular death & 369 & 7.9 & \\
\hline Death from all other causes & 3,096 & 65.9 & \\
\hline
\end{tabular}

Note: column percents may not sum to $100 \%$ due to rounding and nonexhaustive nature of categories. 
Figure 1. Scatterplot of the proportion of the gestation spent in warmest temperature quintile $\left(>13.5^{\circ} \mathrm{C}\right)$, by calendar month of birth, UBCoS participants born 1915 to 1929.

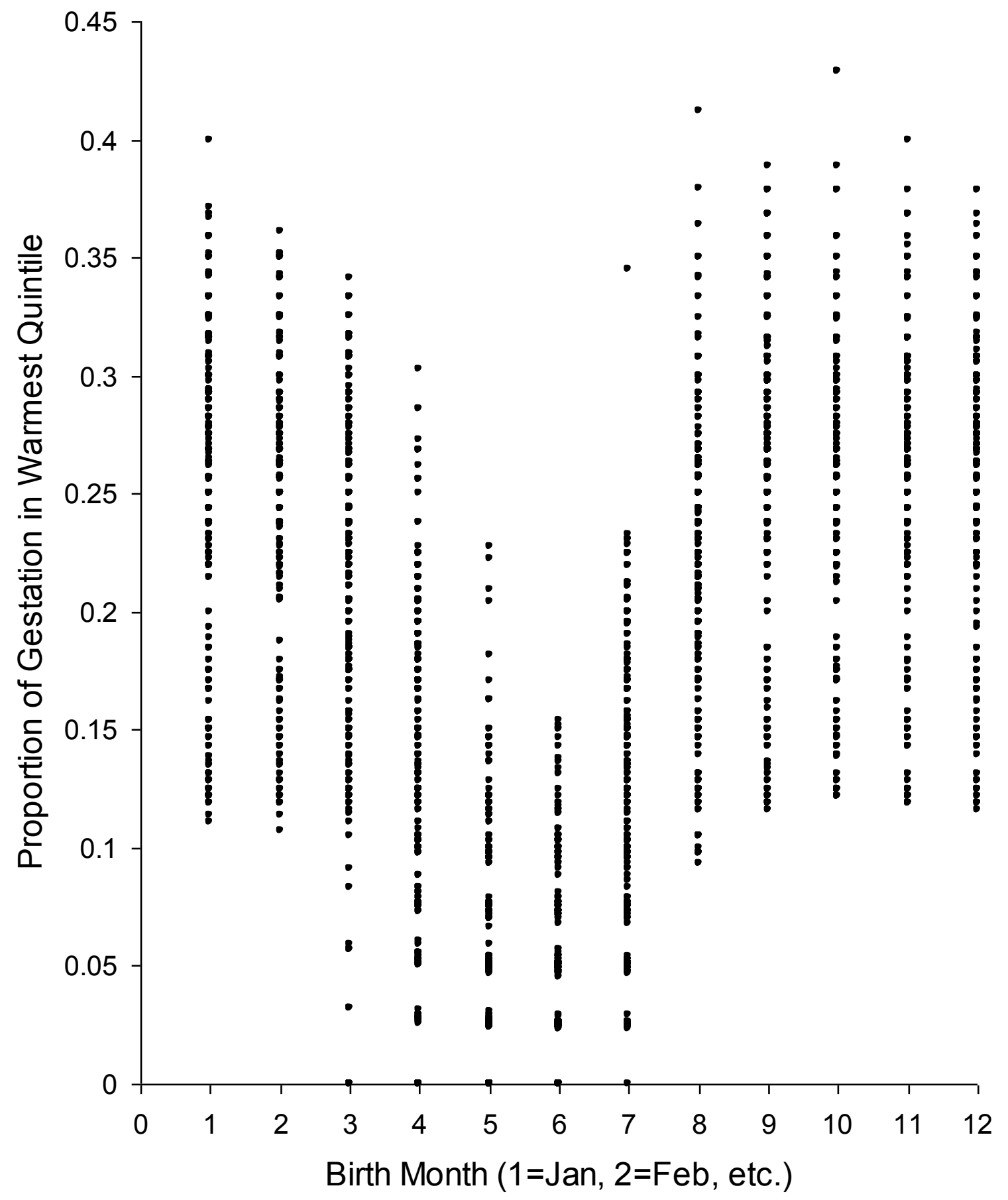


Table 2. Coefficients (95\% Confidence Intervals) for the Cox Proportional Hazards Model of Ischaemic Heart Disease

Death as a Function of Warm Temperature During Gestation, Cold Spells Over the Life Course, the Warm

Gestation/Cold Spell Interaction Term, and Covariates (1,313 IHD Deaths and 540,450 Person-Years of Observation).

Proportion of gestation spent in warmest quintile

Model 1

$0.26(-0.33,0.86)$

$0.07(-0.09,0.24)$

Model 2

Cold spell (referent: non-cold spell)

Warm gestation $x$ Cold spell

Male (referent: Female)

Birth year (continuous)

Calendar month of birth (referent: December)

January

February

March

April

May

June

July

August

September

October

November

Father's occupation (referent: non-manual laborers)

Manual laborers

Entrepreneurs or farmers

Not classified

\section{Model 3}

$-0.41(-1.43,0.61)$

$-0.41(-0.83,0.01)$

$2.47(0.60,4.34)$

$1.12(1.00,1.24)$

$-0.04(-0.05,-0.02)$

$0.28(0.01,0.55)$

$0.28(0.01,0.55)$

$0.12(-0.15,0.39)$

$0.18(-0.11,0.47)$

$0.03(-0.32,0.38)$

$0.12(-0.21,0.45)$

$0.23(-0.08,0.54)$

$0.05(-0.24,0.34)$

$0.19(-0.08,0.46)$

$0.07(-0.22,0.36)$

$0.25(-0.04,0.54)$

$0.14(-0.02,0.30)$

$-0.01(-0.21,0.18)$

$0.16(-0.07,0.39)$ 
Table 3. Coefficients (95\% Confidence Intervals) for the Cox Proportional Hazards Model of Cerebrovascular Disease

(Stroke) Death as a Function of Warm Temperature During Gestation, Cold Spells Over the Life Course, the Warm

Gestation/Cold Spell Interaction Term, and Covariates (406 Stroke Deaths Over 540,450 Person-Years).

Proportion of gestation spent in warmest quintile

Cold spell (referent: non-cold spell)

Warm gestation $x$ Cold spell

Male (referent: Female)

Birth year (continuous)

Calendar month of birth (referent: December)

January
February
March
April
May
June
July
August
September
October
November

Father's occupation (referent: non-manual laborers)

Manual laborers

Entrepreneurs or farmers

Not classified

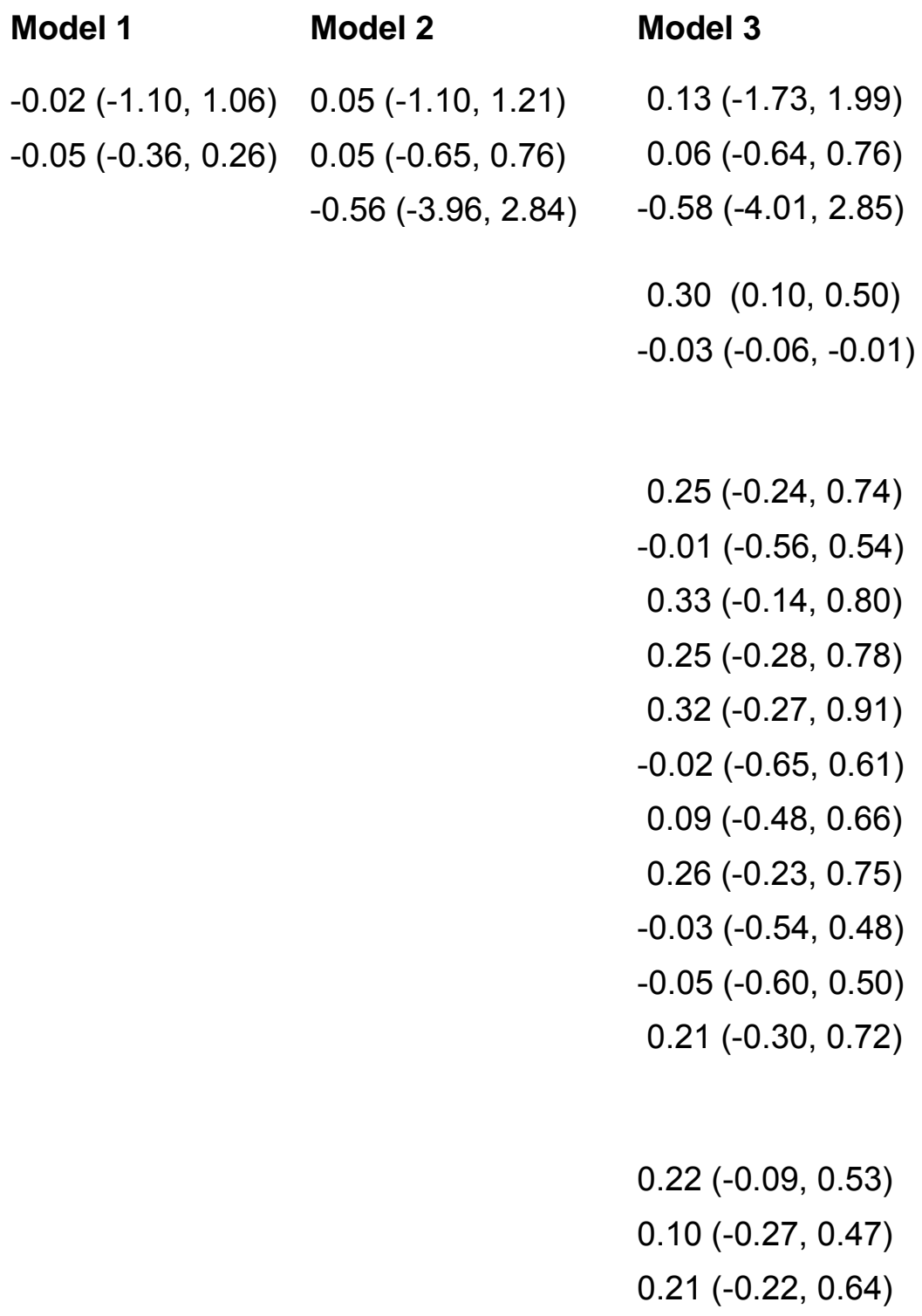

Model 2

$-0.02(-1.10,1.06) \quad 0.05(-1.10,1.21)$

$-0.05(-0.36,0.26) \quad 0.05(-0.65,0.76)$

$-0.56(-3.96,2.84)$

$$
\begin{gathered}
0.30(0.10,0.50) \\
-0.03(-0.06,-0.01)
\end{gathered}
$$

$0.25(-0.24,0.74)$

$-0.01(-0.56,0.54)$

$0.33(-0.14,0.80)$

$0.25(-0.28,0.78)$

$0.32(-0.27,0.91)$

$-0.02(-0.65,0.61)$

$0.09(-0.48,0.66)$

$0.26(-0.23,0.75)$

$-0.03(-0.54,0.48)$

$-0.05(-0.60,0.50)$

$0.21(-0.30,0.72)$

$0.22(-0.09,0.53)$

$0.10(-0.27,0.47)$

$0.21(-0.22,0.64)$ 
Figure 2. Plot of the Hazard Ratio ( $95 \%$ Confidence Intervals in light font) of death due to Ischaemic Heart Disease during a cold spell (vs. non cold spell) across level of warm temperature exposure in utero $(n=1,313$ IHD deaths over 540,450 person-years).

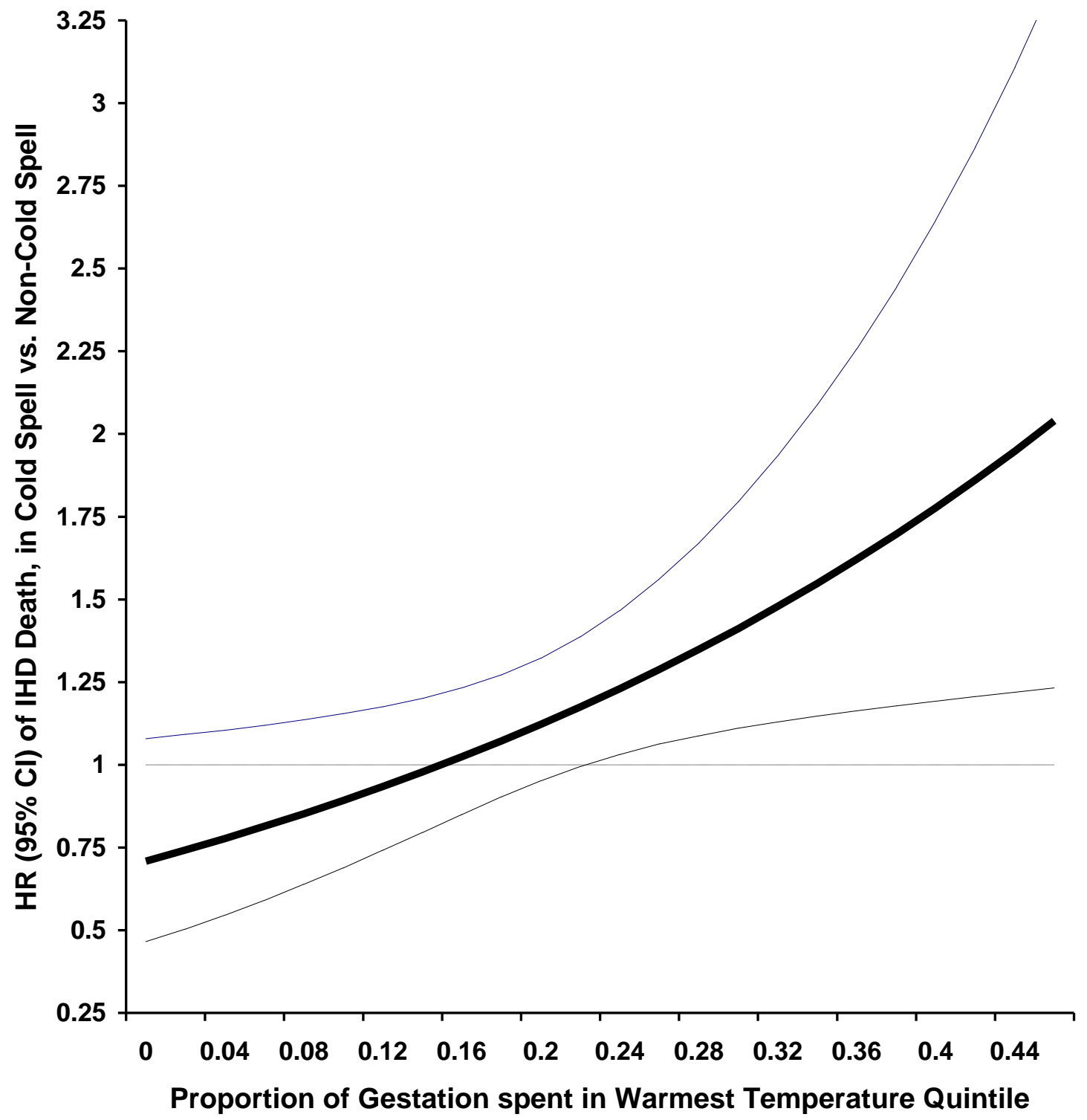

